BMJ Open

Diabetes

Research

\& Care

\title{
Eye care providers' emerging roles in early detection of diabetes and management of diabetic changes to the ocular surface: a review
}

\author{
Kathryn Richdale, ${ }^{1}$ Cecilia Chao (D) , ${ }^{1,2}$ Marc Hamilton ${ }^{3,4}$
}

To cite: Richdale K, Chao C, Hamilton M. Eye care providers' emerging roles in early detection of diabetes and management of diabetic changes to the ocular surface: a review. BMJ Open Diab Res Care 2020;8:e001094. doi:10.1136/ bmjdrc-2019-001094

Received 5 December 2019 Revised 20 March 2020 Accepted 24 March 2020
D) Check for updates

(C) Author(s) (or their employer(s)) 2020. Re-use permitted under CC BY-NC. No commercial re-use. See rights and permissions. Published by BMJ.

\section{${ }^{1}$ College of Optometry,} University of Houston, Houston, Texas, USA

${ }^{2}$ School of Optometry and Vision Science, University of New South Wales-Kensington Campus, Sydney, New South Wales, Australia

${ }^{3}$ Health and Human

Performance, University of Houston, Houston, Texas, USA ${ }^{4}$ Biology and Biochemistry, University of Houston, Houston, Texas, USA

Correspondence to Dr Kathryn Richdale; richdale@uh.edu

\section{ABSTRACT}

US adults visit eye care providers more often than primary healthcare providers, placing these doctors in a prime position to help identify and manage patients with prediabetes and diabetes. Currently, diabetes is identified in eye clinics in an advanced stage, only after visible signs of diabetic retinopathy. Recent ophthalmic research has identified multiple subclinical and clinical changes that occur in the anterior segment of the eye with metabolic disease. The corneal epithelium exhibits increased defects and poor healing, including an increased risk of neurotrophic keratitis. Increased thickness and stiffness of the cornea artificially alters intraocular pressure. There is damage to the endothelial cells and changes to the bacterial species on the ocular surface, both of which can increase risk of complications with surgery. Decreased corneal sensitivity due to a loss of nerve density predispose patients with metabolic disease to further neurotrophic complications. Patients with diabetes have increased Meibomian gland dysfunction, blepharitis and reduced tear production, resulting in increased rates of dry eye disease and discomfort. Early detection of metabolic disease may allow eye care providers to be more proactive in recommending referral and intervention in order to reduce the risk of blindness and other diabetes-related morbidity. Continued research is needed to better understand the time course of changes to the anterior segment and what can be done to better detect and diagnose patients with prediabetes or undiagnosed diabetes and provide improved care for these patients.

\section{INTRODUCTION}

Obesity, prediabetes and diabetes are growing exponentially-worldwide, and especially in the USA. ${ }^{1}$ The effect of diabetes on the retina has been well classified, but there is growing research on the profound effects of metabolic disease on the front of the eye. In the USA, adults visit eye care providers more often than primary healthcare providers, placing eye doctors in a prime position to lead the care and research in this area. ${ }^{2}$ Unfortunately, diabetes is often first diagnosed in eye clinics in an advanced stage, only after visible signs of diabetic retinopathy appear. Standardized, non-invasive, early detection tests in an eye care setting could help to reduce the risk for disease onset and/or progression. The purpose of this paper is to summarize the current state of knowledge on the clinical outcomes of obesity, prediabetes and diabetes on the ocular surface, and explore new research which may someday be applied to help identify and better refer patients with undiagnosed prediabetes and diabetes.

\section{CLINICAL AND SUBCLINICAL CHANGES TO THE OCULAR SURFACE}

New research has identified multiple clinical and subclinical changes that occur in the anterior segment of the eye with dysregulation of insulin and glucose. These alteration can lead to poor or fluctuating vision, increased risk of inflammation and subclinical complications with contact lens wear or ocular surgery and pain and discomfort. The following section reviews changes to the cornea, conjunctiva, eyelids and tear system and are summarized in table 1.

\section{Cornea}

The human cornea is a five-layer structure, comprising an endothelial layer, Descemet's membrane, stroma, basement membrane and epithelium. The cornea is about $540-560 \mu \mathrm{m}$ thick centrally, and increases by about $100 \mu \mathrm{m}$ in the periphery. Central thickness increases by about $10-30 \mu \mathrm{m}$ in patients with type 1 or type 2 diabetes, including well-controlled patients with diabetes with hemoglobin Alc (A1c) $<7 .^{3}$ Duration of diabetes is correlated with increasing corneal thickness. ${ }^{4-7}$ It has been hypothesized that the increase in thickness may be due to increased glucose levels in the tissue and the formation and accumulation of advanced glycation end products (AGEs). ${ }^{5}$ 7-9 Two small population-based studies found no correlation between obesity 
Table 1 Ocular surface changes associated with obesity, prediabetes and diabetes

\begin{tabular}{|c|c|c|c|}
\hline Ocular structure & Obesity & Prediabetes & Diabetes \\
\hline Corneal endothelium & NR & NR & $\begin{array}{l}\text { Decreased cell density } \\
\text { Increased pleomorphism } \\
\text { Increasd polymegathism) } \\
\text { Increase in auto-fluorescence }\end{array}$ \\
\hline $\begin{array}{l}\text { Corneal stroma } \\
\text { (thickness) }\end{array}$ & Increased thickness & NR & $\begin{array}{l}\text { Increased thickness } \\
\text { Increased stiffness (hysteresis) }\end{array}$ \\
\hline Corneal epithelium & NR & NR & $\begin{array}{l}\text { Increased risk of neurotrophic keratitis and } \\
\text { ulceration } \\
\text { Increased number and persistence of defects } \\
\text { Decreased wound healing } \\
\text { Decreased basal and wing cell density } \\
\text { Thickened basement membrane }\end{array}$ \\
\hline $\begin{array}{l}\text { Eyelids and Meibomian } \\
\text { glands }\end{array}$ & NR & NR & $\begin{array}{l}\text { Increased Meibomian gland dysfunction } \\
\text { Increased blepharitis }\end{array}$ \\
\hline $\begin{array}{l}\text { Ocular surface } \\
\text { microbiome }\end{array}$ & NR & NR & $\begin{array}{l}\text { Increased risk of acute bacterial conjunctivitis } \\
\text { Increased levels of positive bacterial culture } \\
\text { Increased bacterial diversity }\end{array}$ \\
\hline $\begin{array}{l}\text { Tear function and eye } \\
\text { symptoms }\end{array}$ & NR & NR & $\begin{array}{l}\text { Decreased tear volume } \\
\text { Decreased tear break-up time } \\
\text { Increased osmolarity } \\
\text { Increased symptoms of dry eye and discomfort }\end{array}$ \\
\hline
\end{tabular}

DC, dendritic cells; NR, not reported.

and corneal thickness ${ }^{10}{ }^{11}$; however, one study reported significant associations between corneal thickness and body weight, body mass index (BMI), fasting plasma glucose (FPG) and 2 hours plasma glucose (PG). ${ }^{12}$ An increase in corneal thickness associated with obesity and prediabetic blood glucose levels are in line with the model of obesity and diabetes being a continuum of metabolic disease. ${ }^{12}$

The corneal endothelium is a single layer of uniform hexagonal squamous cells. The corneal endothelium regulates water and solute transport, including glucose, between the aqueous humor and cornea in order to maintain corneal transparency and thickness. Hyperglycemia can cause direct oxidative damage and reduce the activity of $\mathrm{Na}^{+} / \mathrm{K}^{+}$-ATPase activity. ${ }^{8}$ Corneal endothelial cell density is reduced by about $100-400$ cells $/ \mathrm{mm}^{2}$ in patients with both types 1 and 2 diabetes compared with age-matched controls. ${ }^{4} 581314$ The decrease in density leads to changes in cell shape (pleomorphism) and size (polymegathism). ${ }^{4} 1314$ Duration of diabetes disease is well correlated with endothelial cell density loss, polymegathism and pleomorphism. ${ }^{513}$

The cornea naturally auto-fluoresces at a wavelength of about 515-630 nm when excited with 415-490 nm light due to endogenous fluorophores. ${ }^{15}$ Corneal auto-fluorescence increases in type 1 and 2 diabetes, likely due to the increase in AGEs. ${ }^{16}$ Corneal auto-fluorescence has been correlated with duration of disease, severity of diabetic retinopathy and A1c levels and has been suggested to be a good non-invasive indicator of the metabolic state of the cornea. ${ }^{1617}$

The corneal stroma accounts for the majority of the corneal thickness $(\sim 90 \%)$ and thus its physical and biomechanical properties. Hyperglycemia and associated accumulation of AGEs lead to crosslinking of the stroma which increases the corneal stiffness. ${ }^{9}$ Patients with type 1 and type 2 diabetes have been shown to have increased corneal hysteresis, or viscosity, of the cornea as measured by resistance to deformation by air puff. ${ }^{6}{ }^{18}$ Corneal hysteresis is also associated with the duration of disease and A1c levels. ${ }^{718}$ Increased corneal thickness and stiffness in patients with diabetes can lead to an overestimation of intraocular pressure (IOP) ${ }^{719}$ which may lead to a misdiagnosis of glaucoma.

The cornea is the most densely innervated tissue in the body, with about 7000 nociceptors $/ \mathrm{mm}^{2}$ at its center. ${ }^{20}$ Corneal nerves derive from the nasociliary branch of the ophthalmic division of the trigeminal nerve (cranial nerve $\mathrm{V}$ ), enter through the anterior stroma as small unmyelinated nerve fibers and then branch upward to 

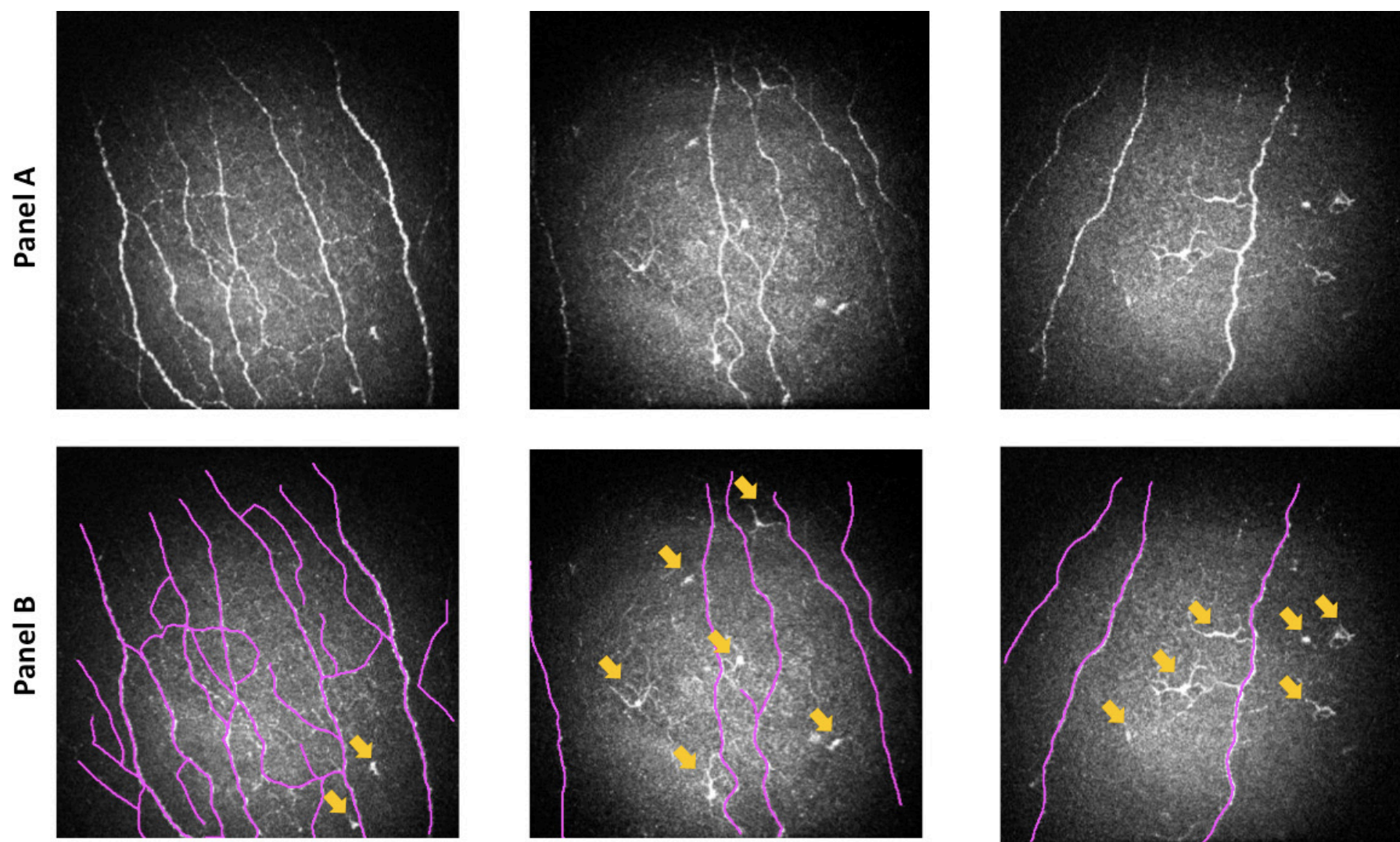

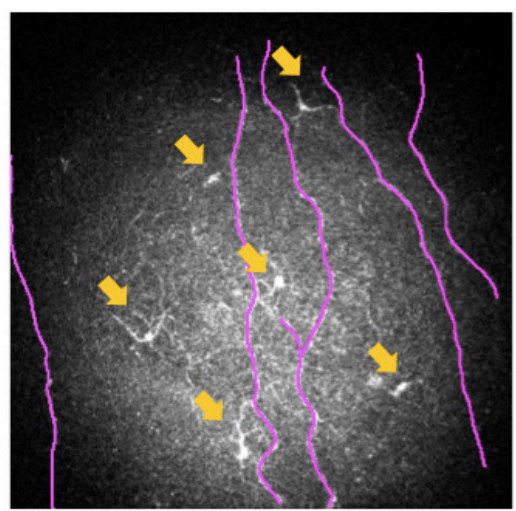

B. Prediabetes

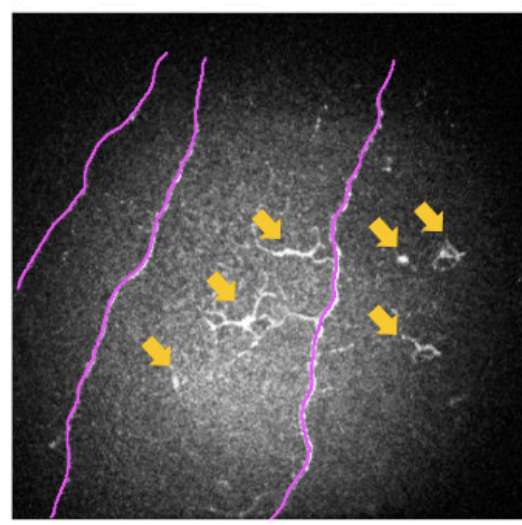

C.
Diabetes
A. No metabolic disease

Figure 1 In vivo corneal confocal images $\left(400 \times 400 \mu \mathrm{m}^{2}\right)$ demonstrating patients with (A) no metabolic disease, (B) prediabetes and $(C)$ type 2 diabetes (panel A) at the central cornea. Corneal subbasal sensory nerves are highlighted in purple in panel B with calculated densities of $3964 \mu \mathrm{m}, 1691 \mu \mathrm{m}$ and $1012 \mu \mathrm{m}$ per $400 \times 400 \mu \mathrm{m}^{2}$ in patients with no metabolic disease (A), prediabetes (B) and diabetes (C), respectively (Richdale and Harrison, unpublished data). Yellow arrows indicate corneal epithelial dendritic cells and show a higher density in patients with prediabetes and diabetes (6 cells/frame) compared with those with no metabolic disease (2 cells/frame). All subjects were 54-59 years of age with no history of contact lens wear. Photo credit: Labs of Kathryn Richdale, OD, PhD and Wendy Harrison, OD, PhD, College of Optometry, University of Houston, Texas, USA.

penetrate basement membrane layer, form the subbasal nerve plexus and terminate in the epithelium. ${ }^{20}$ Corneal nerves regulate wound healing and modify the lacrimal response, and are critical to ocular surface integrity. ${ }^{21}$ Corneal subbasal nerves can be imaged non-invasively with in vivo confocal microscopy. Corneal subbasal nerve fiber length, density and branching are reduced with type
1 and 2 diabetes (figure 1). ${ }^{22-25}$ The decrease in corneal nerve fiber length and density has been well correlated with diabetic peripheral neuropathy ${ }^{2425}$ and autonomic neuropathy. ${ }^{26}$ Due to the nerve and other ocular surface damage, up to $70 \%$ of patients with diabetes have some form of keratitis ranging from superficial punctate keratitis to recurrent corneal erosions and neurotrophic

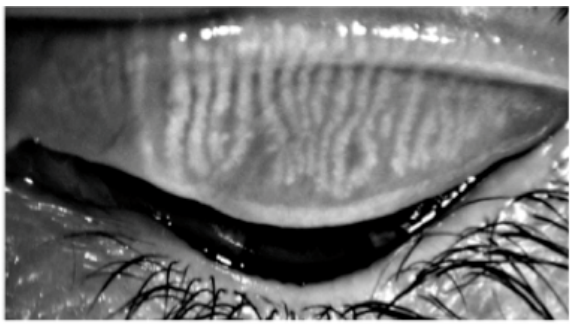

\section{A. No metabolic disease}

B.
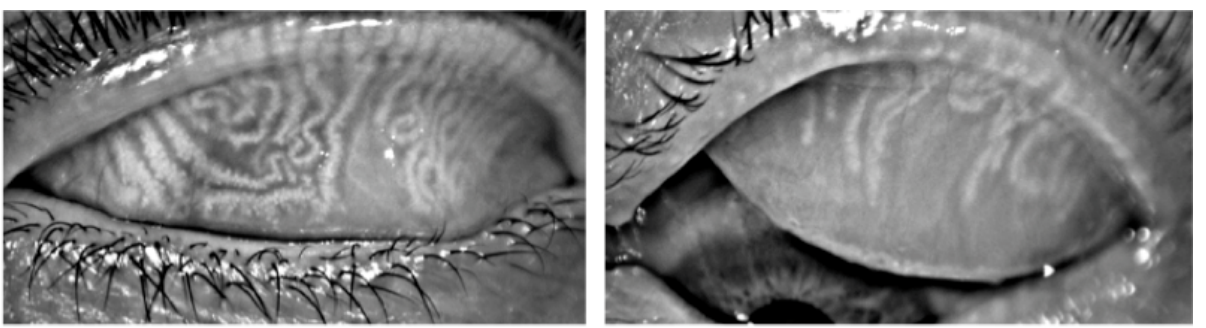

C.

\section{Diabetes} metabolic disease, (B) prediabetes and (C) type 2 diabetes (Richdale and Harrison, unpublished data). All subjects are 51-59 years of age with mild-to-moderate dry eye symptoms and did not wear contact lenses. Photo credit: Labs of Kathryn Richdale, OD, PhD and Wendy Harrison, OD, PhD, College of Optometry, University of Houston, Texas, USA. 
ulcer $^{27-29}$ (figure 2). Corneal nerve fiber length was predictive of a diagnosis of peripheral neuropathy in patients with diabetes, with a cut-off point of $12 \mathrm{~mm} /$ $\mathrm{mm}^{2}{ }^{30}$ Importantly, corneal nerve health was shown to improve with improved glucose control for patients with either type 1 or type 2 diabetes. ${ }^{31} 32$

Corneal sensitivity to mechanical pressure, temperature and chemicals stimuli is a measure of corneal nerve function. ${ }^{33}$ More than $50 \%$ of the patients with diabetes show reduced sensitivity as a result of damage to corneal sensory nerve. ${ }^{34}$ All three types of sensitivity are reduced in patients with long-term type 1 and type 2 diabetes. ${ }^{23} 35$ Decreases in mechanical sensitivity measured by noncontact esthesiometer were noted shortly after diagnosis of type 2 diabetes, but were somewhat delayed for those with type 1 diabetes, which also mimics patterns seen in peripheral neuropathy. ${ }^{35}$

Corneal epithelial dendritic cells are antigen-presenting cells located in and around the corneal subbasal epithelial layer and initiate the immune response to infectious or inflammatory agents. ${ }^{23}{ }^{36}$ Dendritic cells are critical for proper corneal epithelial wound healing. ${ }^{37}$ These cells can be identified by their morphology in vivo with confocal microscopy (figure 1). There is an increase in central dendritic cell density in patients with type 1 and 2 diabetes compared with healthy controls. ${ }^{22}{ }^{38}$ Dendritic cell density has also been found to be inversely related to corneal nerve fiber density, ${ }^{22} 38$ indicating that there may be a neuro-immune interaction in the development of the neurotrophic keratitis.

The corneal epithelium is about $50 \mu \mathrm{m}$ thick with layers of squamous, intermediate (wing) and basal cells, which are attached to the underlying basement membrane by hemidesmosomes. In vivo confocal microscopy has been used to measure the density of intermediate and basal epithelial cells in diabetes. The epithelial cell density is reduced in patients with type 1 and type 2 diabetes, with each year of diabetes corresponding to a decrease of about $10-25$ cells $/ \mathrm{mm}^{2}{ }^{39}{ }^{40}$ The corneal basement membrane also becomes thicker and less regular, and junctions between cells are weakened in diabetes. ${ }^{28} 41$ There are direct and indirect effects of changes in glucose and insulin on the structure and metabolism of the corneal epithelium. ${ }^{42}$ In brief, hyperglycemia alters the expression of growth factors and mediators secreted by corneal epithelial cells, leading to a cyclic disruption in cell growth, migration and integrity. ${ }^{42}$ Early research suggested that the corneal epithelium does not require insulin for uptake of glucose ${ }^{43}$; however, recent research using human telomerized corneal epithelial cells in culture suggests that insulin plays a key role in mediating epithelial cell metabolism and homeostasis. ${ }^{44}$

Although the early effects of obesity or prediabetes on corneal health have not been well explored, given the continuum of diseases seen in other aspects of the body, it is likely that the structure and function of the entire cornea is altered before the diagnosis of diabetes. Further research is needed to fully understand the potential effects of early disease states on corneal health. One major gap pertains to the possible ability of interventions that reverse glucose dysregulation, in either people with prediabetes or obesity, to improve corneal nerve health and adverse immune response, which could lead to improved corneal wound healing and reduce the risk of further damage. Some lifestyle strategies, such as increased physical activity and diet, can rapidly reduce glucose levels and postprandial insulin before and independent of weight changes. Thus, it will also be important to understand the time course of disease development for corneal health. The progression from impaired glucose tolerance or fasting hyperglycemia on through diagnosed diabetes may indicate that some of the ocular pathology occurs sooner in the spectrum of disease than the classical clinical symptoms or retinal signs at the diagnosis of diabetes. And because of this, it follows that there is a need to know if there is also a rapid attenuation or reversal in the anatomy and physiology in the eye, as there might be for adaptations in the peripheral vasculature.

\section{Tear film, conjunctiva, eyelid and Meibomian glands}

The ocular surface produces lipid, aqueous and mucin, to make up the tear film, which is then spread by the eyelids and serves to protect and maintain the health of the ocular surface. The aqueous layer is primarily produced by the lacrimal and accessory glands. Mucins are secreted by the conjunctival goblet cells and corneal epithelial cells. Lipids are secreted from the Meibomian glands, which are located in the eyelids.

The International Dry Eye Workshop (DEWS) II report classified diabetes as a risk factor for aqueousdeficient dry eye disease, although it may also have an evaporative component. ${ }^{45}{ }^{46}$ Patients with type 1 and 2 diabetes have been shown to have a faster tear break up time, decreased tear production and volume, higher tear osmolarity and greater rates of Meibomian gland dysfunction (figure 2). ${ }^{24}{ }^{47-50}$ The ocular surface is further compromised in patients with more severe and longer duration of diabetes disease, including those with higher Alc values, or retinopathy or peripheral neuropathy. ${ }^{24} 51$ Patients with obesity (average BMI 38.2 \pm 5.8 ), most of whom would also have been classified as having prediabetes (FPG 108.2 \pm 14.1 ), also showed increased conjunctival metaplasia and goblet cell loss compared with healthy controls. ${ }^{52}$ Via a retrospective medical record review, patients with diabetes were more likely to have a diagnosis of blepharitis (type unspecified) compared with controls. ${ }^{53}$ The etiology and pathogenesis of reduced tear function in patients with diabetes is likely due to both microvascular and neuropathic changes in lacrimal and Meibomian glands, in addition to reduction in reflex tearing due to decreased corneal sensitivity and nerve dysfunction. ${ }^{45} 54$

Patients with type 1 and 2 diabetes may also have more conjunctival hyperemia, due to a dilation of the large conjunctival vessels. ${ }^{556}$ At the same time, the smaller 
capillary vessels have been found to decrease in diameter in patients with diabetes. ${ }^{55}$ The increase in conjunctival microvasculopathy was identified even prior to the onset of clinical retinopathy. ${ }^{56}$ Further testing is needed to understand the relationship between conjunctival and retinal microvasculopathy but, due to the non-invasive nature of the testing, conjunctival microvascular testing could be a useful screening tool for early diabetic retinal disease. $^{56}$

A detailed review of tear components modified by diabetes and other diseases has been published elsewhere and is beyond the scope of this paper. ${ }^{57}$ But, in brief, many tear inflammatory mediators and neuropeptide (eg, substance $\mathrm{P}$ ) are altered in diabetes but there are no significant changes in the main tear proteins, including lactoferrin, albumin, lipocalin, lysozyme and secretary IgA. ${ }^{58}{ }^{59}$ Tear glucose levels also are higher in patients with type 1 or 2 diabetes under both fasting and fed conditions compared with healthy controls. ${ }^{60-62}$ Tear glucose levels are about 10 times lower but well correlated with blood glucose levels, after allowing approximately 20-25 min for equilibration. ${ }^{606163}$ Average tear glucose concentration of patients without diabetes range from about 0.05 to $0.5 \mathrm{mM}(0.89-8.9 \mathrm{mg} / \mathrm{dL})$, and 0.5 to $5 \mathrm{mM}(9.0-89.3 \mathrm{mg} / \mathrm{dL})$ for patients with diabetes. ${ }^{60} 63$ Unfortunately, there is no known report of tear glucose levels for patients with prediabetes. Insulin is critical to maintaining the health of the cornea, lacrimal glands and Meibomian glands. ${ }^{42} 5464$ However, there is only one study which reported insulin levels in human tears. Rocha et al found that insulin levels in stimulated tears of patients without diabetes were approximately $0.20 \mathrm{ng} /$ $\mathrm{mL}(69 \mathrm{pmol} / \mathrm{L})$ under fasting conditions and increased to $0.60 \mathrm{ng} / \mathrm{mL}(103 \mathrm{pmol} / \mathrm{L})$ after a meal. ${ }^{65}$ Insulin levels in tears of patients with diabetes, prediabetes or obesity have not been reported. In general, insulin-like growth factor binding protein 3 (IGPBP3) binds to insulin-like growth factor-1 in order to activate the cell apoptosis and antiproliferation. ${ }^{39}{ }^{66}$ Since the expression of IGPBP3 was found to be greatly increased in patients with type 2 diabetes, compared with controls and was negatively correlated with corneal nerve fiber length, it has been proposed that IGPBP3 plays an important role in corneal epithelial and nerve health in type 2 diabetes. ${ }^{3966}$ There was a similar, although not statistically significant trend for patients with type 1 diabetes. ${ }^{66}$

The predominant microbial species identified on the healthy ocular surface are Corynebacterium, Staphylococcus, Streptococcus, Acinetobacterand Pseudomonas. ${ }^{67}$ High glucose levels in the tears and increased ocular surface inflammation with diabetes support increased microbial growth. ${ }^{68}$ Using traditional culture techniques, greater frequency of Escherichia coli, Klebsiella pneumoniae and enterococci have been identified on the ocular surface of patients with diabetes compared with healthy controls. ${ }^{69-71}$ Higher positive culture rates and greater bacterial diversity were associated with increasing severity and duration of diabetes disease, respectively. ${ }^{70}$ Using $16 \mathrm{~s}$ rRNA analysis, patients with type 2 diabetes were found to have greater bacterial diversity and increased abundance of Acinetobacter, Pseudomonas, Burkholderia, Sphingomonas and Ralstonia compared with healthy controls. ${ }^{68} 73$ Patients with type 1 and type 2 diabetes have been shown to have an increased risk of acute bacterial conjunctivitis. ${ }^{53} 74$ Further research in larger and more diverse populations is needed to fully understand the effects of these diseases on the ocular surface microbiome and risk for ocular inflammation.

\section{EYE CARE FOR PATIENTS WITH DIABETES AND AT-RISK POPULATIONS}

The American Optometric Association and the American Academy of Ophthalmology recommend that patients with diabetes receive a comprehensive eye exam at diagnosis of type 2 diabetes or 5 years after diagnoses of type 1 diabetes, and then annually thereafter. ${ }^{7576}$ Patients with diabetic retinopathy should be seen more frequently. ${ }^{75} 76$ There are no specific guidelines for patients with prediabetes or obesity. Therefore, one of the pressing needs for more research is to define the time course of the ocular pathological changes prior to diabetes diagnosis. As discussed in the previous section, identifying potential metabolic disease changes earlier may allow for treatment and possible reversal of pathological processes which could have a significant impact on ocular and overall systemic health and quality of life.

According to US optometry and ophthalmology guidelines, care of the patient with diabetes is focused on diagnosing and managing retinal complications. ${ }^{75} 76$ Currently, the recommendations for anterior segment complications associated with diabetes are to monitor and manage as usual and customary as there are no disease-specific treatments. ${ }^{76}$ Epithelial defects and dry eye disease can be managed with ophthalmic lubricants, punctal plugs, prescription topical or oral medications, autologous serum, amniotic membranes or lid closure. ${ }^{46}$ Bandage or scleral contact lenses may be used with caution due to increased risk of infections. Nonsteroidal anti-inflammatory drugs should be avoided in these patients due to the possibility of corneal perforation. ${ }^{20}$ Some experimental treatments have begun to be evaluated in early human case reports and trials. Despite a lack of understanding of the normal levels of insulin in non-diabetic and diabetic tears, it has been shown that the use of topical insulin improved time to wound healing, compared with standard treatment of antibiotic and steroid, following corneal debridement during vitreoretinal surgery in patients with diabetes. ${ }^{77} 78$ Thymosin beta4 ( $\beta 4$ ) has multiple regenerative properties and has been used to heal pressure and venous stasis ulcers and improve dry eye signs and symptoms. ${ }^{79} 80$ Thymosin $\beta 4$ has also been suggested to promote wound healing in a case series of patients with diabetes. ${ }^{81} 82$

There is only one Food and Drug Administrationapproved treatment for neurotrophic keratitis, the 
most severe type of keratitis caused by corneal nerve damage, Oxervate (cenegermin). Oxervate is a recombinant human nerve growth factor, was found to improve neurotrophic keratitis in $70 \%$ of patients compared with placebo $(28 \%) \cdot{ }^{83}$ However, it is a costly treatment and may not be accessible to all patients. Current research is also exploring the potential use of aldose reductase inhibitors, opioid growth factors, hepatocyte growth factors and other topical therapies for neurotrophic keratitis. ${ }^{2084}$ Unfortunately, the standard of care for patients with anterior segment complications of diabetes is still mainly palliative, based on symptoms, and uses therapies researched mostly on patients without diabetes.

The effects of contact lens wear and diabetes have been carefully reviewed by O'Donnell and Efron and Bussan and Robertson. ${ }^{85} 86$ Patients with diabetes who wear soft contact lenses had about 130 cells $/ \mathrm{mm}^{2}$ fewer endothelial cells than patients with diabetes who do not wear lenses, ${ }^{4}$ which is a $4 \%-5 \%$ greater loss of endothelial cells for patients with diabetes compared with healthy adults. Patients with diabetes who do not wear contact lenses had about 370 endothelial cells $/ \mathrm{mm}^{2}$ less than healthy non-contact lens wearers. ${ }^{4}$ This suggests that patients with diabetes who wear soft contact lenses longterm may suffer further endothelial compromise than either factor alone. ${ }^{47}$ Rigid gas permeable contact lenses offer improved oxygen transmission and reduced risk of infections thus should potentially offer patients with diabetes improved outcomes. However, there is limited research beyond clinical observations of the potential complications of rigid contact lens wear in patients with diabetes. ${ }^{85} 86$ The current US ophthalmic guidelines do not preclude contact lens wear for patients with diabetes. Nevertheless, eye doctors are encouraged to educate patients with diabetes on the increased risk of complications and more frequent follow-up is recommended due to poorer wound healing, reduced corneal nerve function, decreased endothelial cell density and changes in the ocular microbiome, ${ }^{475}$ which may lead to contact lens indicated corneal infiltrative events.

Patients with diabetes may be at increased risk of complications during and after ocular surgery. Patients with diabetes suffer about 4\%-6\% greater endothelial cell loss after cataract surgery, with greater cell loss being reported in patients with longer duration of disease. ${ }^{14} 8889$ Fortunately, the additional cell density loss did not seem to affect visual acuity. ${ }^{88}$ Patients with diabetes have higher rates of incomplete wound healing after laser-assisted keratomileusis (LASIK). ${ }^{90}$ Due to unstable refractive error associated with hyperglycemia, patients with uncontrolled diabetes have worse refractive outcomes. ${ }^{91-93}$ Halkiadakis et al reported no significant difference in clinical outcomes for patients with diabetes with good glycemic control undergoing LASIK. ${ }^{94}$ The American Academy of Ophthalmology considers uncontrolled diabetes an absolute contraindication, but well-controlled diabetes a relative contraindication for refractive surgery. ${ }^{91}$ Further research is needed to fully understand the effects of metabolic disease on postsurgical pain and wound healing.

The Eye Bank Association of America does not require indicating diabetes as a possible contributing factor to donor death, and historical data suggest that donor corneas from patients with reported diabetes is not a risk factor for penetrating keratoplasty failure. ${ }^{95}$ However, a recent study found that donor corneas from patients with obesity and diabetes were more likely to lead to graft failure in Descemet Membrane Endothelial Keratoplasty surgery. ${ }^{96} 97$ Thus, continued research is needed to fully understand the risks for patients who are recipients of corneas from donors with metabolic disease.

\section{SUMIMARY OF LIMITATIONS IN RESEARCH AND CLINICAL CARE}

Research in diabetes in the eye has historically been focused on the retina. More recently, researchers have begun to explore the effects of type 1 and 2 diabetes on the anterior segment of the eye and revealed significant structural and functional alterations, including dry eye disease, even early in the disease process. Populationbased studies would be required to confirm the effect of diabetes on dry eye. Corneal subbasal nerves are readily imaged with in vivo confocal microscopy and able to reveal early neuropathy and regeneration with treatment. Corneal auto-fluorescence and tear protein and neuropeptide levels may be other non-invasive methods to screen and monitor disease severity and evaluate efficacy of treatments. Unfortunately, ocular surface diabetes research continues to lag behind systemic research as there is still a limited understanding of the course of the disease from obesity and prediabetes up through later stages of the disease when retinal damage is visible. With earlier detection and education of ocular pathological events, patients may be more motivated to take action to improve overall health and prevent loss of vision, which is considered by patients as more devastating than loss of a limb, memory, hearing or speech. ${ }^{98}$

Current anterior segment care is palliative and does nothing to stop or reverse the damage induced by diabetes. There are no guidelines for eye care for patients with obesity or prediabetes. While only severe diseases such as neurotrophic or bacterial keratitis have the potential to cause permanent visual loss, other changes to the cornea, conjunctiva, lids and tear function can lead to chronic discomfort, pain and fluctuations in vision which can have a significant impact on patients' quality of life. More research is needed to understand if any current or novel treatments could halt or reverse the effects of metabolic disease on the eye.

Given the staggering numbers of undiagnosed patients with prediabetes and diabetes in the USA, better early screening test are needed. The ideal screening tests would be low cost, non-invasive and have high sensitivity and specificity. While the American Diabetes Association (ADA) recommends Alc testing for all patients over the age of 45 years and for overweight adults of any age, many 
of the most at-risk patients are not seeking preventative primary care and thus remain undiagnosed. Although we may be years away from eye tests that are incorporated into ADA recommendations for eye doctors to use routinely, recent ophthalmic research has begun to identify promising tests to elucidate multiple subclinical and clinical changes associated with diabetes in the anterior segment of the eye, including readily detectable changes in corneal thickness, stiffness and nerve density. Incorporating these tests into routine eye care could allow eye doctors to better understand the course of the disease process. Other changes such as corneal auto-fluorescence, conjunctival microvasculature and tear components are not currently feasible to conduct during routine eye care but could 1 day become biomarkers with the development of better clinical tools to accurately detect and monitor changes. This has been the case in other areas such as the InflammaDry (Quidel, San Diego, California, USA) for testing matrix metallopeptidase-9 levels in patients with dry eye. Continued research is needed to determine which clinical parameters and cut-off points could help practitioners improve the specificity and sensitivity of screening tools like the ADA risk questionnaire to identify patients at greatest risk. Therefore, this review is intended to provide clinicians and researchers with information about early anterior segment changes that may, someday, further help the detection of diabetes for patients in eye clinics. Most of the studies to date have included only patients with established diabetes already under treatment. Thus, it is not clear which of the anterior segment biomarkers might best be associated with early diabetes disease and could be further developed to improve screening and detection of patients with prediabetes or early undiagnosed diabetes. Continued research and analysis of anterior segment changes in patients with prediabetes and diabetes could ultimately help eye care providers identify and make more appropriate referrals long before the onset of diabetic retinopathy. Longitudinal studies of patients from the stage of obesity, or prediabetes, or the initial diagnosis of diabetes, would allow researchers to understand the mechanism underlying the impact of hyperglycemia and insulinemia on the ocular surface tissues.

In summary, given the epidemic rates of obesity, prediabetes and diabetes in the USA, there is a strong need for continued research to understand the anterior segment complication of metabolic disease and improve both diagnosis and treatment options for patients.

Acknowledgements The authors would like to thank the students from Richdale's and Harrison's lab, University of Houston, College of Optometry shared the photos for this review paper.

Contributors All authors have contributions to the conception of the review, including drafting the work or revising it critically for important intellectual content. All authors have given final approval of the reversion published.

Funding The authors have not declared a specific grant for this research from any funding agency in the public, commercial or not-for-profit sectors.

Competing interests None declared.
Patient consent for publication Not required.

Provenance and peer review Not commissioned; externally peer reviewed.

Data availability statement No data are available.

Open access This is an open access article distributed in accordance with the Creative Commons Attribution Non Commercial (CC BY-NC 4.0) license, which permits others to distribute, remix, adapt, build upon this work non-commercially, and license their derivative works on different terms, provided the original work is properly cited, appropriate credit is given, any changes made indicated, and the use is non-commercial. See: http://creativecommons.org/licenses/by-nc/4.0/.

ORCID iD

Cecilia Chao http://orcid.org/0000-0001-7665-0569

\section{REFERENCES}

1 WHO. World Health organization global report on diabetes. Geneva, Switzerland, 2016: 1-88.

2 United Health Care. Impact of eye exams in identifying chronic conditions, 2014. Available: https://www.uhc.com/content/dam/ uhcdotcom/en/Private Label Administrators/vision-white-paper-2014 Impact of Eye Exams.pdf [Accessed Aug 2019].

3 Sanchis-Gimeno JA, Alonso L, Rahhal M, et al. Corneal thickness differences between type 2 diabetes and non-diabetes subjects during preoperative laser surgery examination. J Diabetes Complications 2017;31:209-12.

4 Leem HS, Lee KJ, Shin KC. Central corneal thickness and corneal endothelial cell changes caused by contact lens use in diabetic patients. Yonsei Med J 2011;52:322-5.

5 Calvo-Maroto AM, Cerviño A, Perez-Cambrodí RJ, et al. Quantitative corneal anatomy: evaluation of the effect of diabetes duration on the endothelial cell density and corneal thickness. Ophthalmic Physiol Opt 2015;35:293-8.

6 Goldich Y, Barkana Y, Gerber Y, et al. Effect of diabetes mellitus on biomechanical parameters of the cornea. $J$ Cataract Refract Surg 2009;35:715-9.

7 Scheler A, Spoerl E, Boehm AG. Effect of diabetes mellitus on corneal biomechanics and measurement of intraocular pressure. Acta Ophthalmol 2012;90:e447-51.

8 McNamara NA, Brand RJ, Polse KA, et al. Corneal function during normal and high serum glucose levels in diabetes. Invest Ophthalmol Vis Sci 1998;39:3-17.

9 Bao F, Deng M, Zheng X, et al. Effects of diabetes mellitus on biomechanical properties of the rabbit cornea. Exp Eye Res 2017; 161:82-8

10 Gunes A, Uzun F, Karaca EE, et al. Evaluation of anterior segment parameters in obesity. Korean J Ophthalmol 2015;29:220-5.

11 Panon N, Luangsawang K, Rugaber C, et al. Correlation between body mass index and ocular parameters. Clin Ophthalmol 2019:13:763-9.

12 Nishitsuka K, Kawasaki R, Kanno M, et al. Determinants and risk factors for central corneal thickness in Japanese persons: the Funagata study. Ophthalmic Epidemiol 2011;18:244-9.

13 Islam QU, Mehboob MA, Amin ZA. Comparison of corneal morphological characteristics between diabetic and non diabetic population. Pak J Med Sci 2017;33:1307-11.

14 Dhasmana R, Singh IP, Nagpal RC. Corneal changes in diabetic patients after manual small incision cataract surgery. J Clin Diagn Res 2014;8:VC03-6.

15 Van Schaik HJ, Coppens J, Van den Berg TJ, et al. Autofluorescence distribution along the corneal axis in diabetic and healthy humans. Exp Eye Res 1999;69:505-10.

16 Calvo-Maroto AM, Perez-Cambrodi RJ, Garcia-Lazaro S, et al. Ocular autofluorescence in diabetes mellitus. A review. J Diabetes 2016;8:619-28.

17 Ishiko S, Yoshida A, Mori F, et al. Corneal and lens autofluorescence in young insulin-dependent diabetic patients. Ophthalmologica 1998:212:301-5.

18 Hager A, Wegscheider K, Wiegand W. Changes of extracellular matrix of the cornea in diabetes mellitus. Graefes Arch Clin Exp Ophthalmol 2009;247:1369-74.

19 Schweitzer C, Korobelnik J-F, Boniol M, et al. Associations of biomechanical properties of the cornea with environmental and metabolic factors in an elderly population: the ALIENOR study. Invest Ophthalmol Vis Sci 2016;57:2003-11.

20 Shaheen BS, Bakir M, Jain S. Corneal nerves in health and disease. Surv Ophthalmol 2014;59:263-85.

21 Stern ME, Gao J, Siemasko KF, et al. The role of the lacrimal functional unit in the pathophysiology of dry eye. Exp Eye Res 2004;78:409-16. 
22 Qu J-H, Li L, Tian L, et al. Epithelial changes with corneal punctate epitheliopathy in type 2 diabetes mellitus and their correlation with time to healing. BMC Ophthalmol 2018;18:1

23 Zhivov A, Winter K, Hovakimyan M, et al. Imaging and quantification of subbasal nerve plexus in healthy volunteers and diabetic patients with or without retinopathy. PLoS One 2013;8:e52157.

24 DeMill DL, Hussain M, Pop-Busui R, et al. Ocular surface disease in patients with diabetic peripheral neuropathy. Br J Ophthalmol 2016;100:924-8

25 Jiang M-S, Yuan Y, Gu Z-X, et al. Corneal confocal microscopy for assessment of diabetic peripheral neuropathy: a meta-analysis. $\mathrm{Br} \mathrm{J}$ Ophthalmol 2016;100:9-14

26 Misra SL, Craig JP, Patel DV, et al. In vivo confocal microscopy of corneal nerves: an ocular biomarker for peripheral and cardiac autonomic neuropathy in type 1 diabetes mellitus. Invest Ophthalmol Vis Sci 2015;56:5060-5.

27 Inoue K, Okugawa K, Amano S, et al. Blinking and superficial punctate keratopathy in patients with diabetes mellitus. Eye 2005;19:418-21.

28 Rehany U, Ishii Y, Lahav M, et al. Ultrastructural changes in corneas of diabetic patients: an electron-microscopy study. Cornea 2000;19:534-8.

29 Hyndiuk RA, Kazarian EL, Schultz RO, et al. Neurotrophic corneal ulcers in diabetes mellitus. Arch Ophthalmol 1977;95:2193-6.

30 Perkins BA, Lovblom LE, Bril V, et al. Corneal confocal microscopy for identification of diabetic sensorimotor polyneuropathy: a pooled multinational Consortium study. Diabetologia 2018;61:1856-61.

31 Azmi S, Ferdousi M, Petropoulos IN, et al. Corneal confocal microscopy shows an improvement in small-fiber neuropathy in subjects with type 1 diabetes on continuous subcutaneous insulin infusion compared with multiple daily injection. Diabetes Care 2015;38:e3-4

32 Jia $X$, Wang $X$, Wang $X$, et al. In vivo corneal confocal microscopy detects improvement of corneal nerve parameters following glycemic control in patients with type 2 diabetes. J Diabetes Res 2018;2018:1-8.

33 Belmonte C, Acosta MC, Schmelz M, et al. Measurement of corneal sensitivity to mechanical and chemical stimulation with a $\mathrm{CO} 2$ esthesiometer. Invest Ophthalmol Vis Sci 1999;40:513-9.

34 Premkumar LS, Pabbidi RM. Diabetic peripheral neuropathy: role of reactive oxygen and nitrogen species. Cell Biochem Biophys 2013;67:373-83

35 Neira-Zalentein W, Holopainen JM, Tervo TMT, et al. Corneal sensitivity in diabetic patients subjected to retinal laser photocoagulation. Invest Ophthalmol Vis Sci 2011;52:6043-9.

36 Mastropasqua L, Nubile M, Lanzini M, et al. Epithelial dendritic cell distribution in normal and inflamed human cornea: in vivo confocal microscopy study. Am J Ophthalmol 2006;142:736-44.

37 Gao N, Yin J, Yoon GS, et al. Dendritic cell-epithelium interplay is a determinant factor for corneal epithelial wound repair. Am J Pathol 2011;179:2243-53.

38 Tavakoli M, Boulton AJM, Efron N, et al. Increased Langerhan cell density and corneal nerve damage in diabetic patients: role of immune mechanisms in human diabetic neuropathy. Cont Lens Anterior Eye 2011;34:7-11.

39 Stuard WL, Titone R, Robertson DM. Tear levels of insulin-like growth factor binding protein 3 correlate with subbasal nerve plexus changes in patients with type 2 diabetes mellitus. Invest Ophthalmol Vis Sci 2017;58:6105-12.

40 Dehghani C, Pritchard N, Edwards K, et al. Abnormal Anterior Corneal Morphology in Diabetes Observed Using In Vivo Laserscanning Confocal Microscopy. Ocul Surf 2016;14:507-14.

41 Ljubimov AV, Huang ZS, Huang GH, et al. Human corneal epithelial basement membrane and integrin alterations in diabetes and diabetic retinopathy. J Histochem Cytochem 1998;46:1033-41.

42 Zhu L, Titone R, Robertson DM. The impact of hyperglycemia on the corneal epithelium: molecular mechanisms and insight. Ocul Surf 2019;17:644-54.

43 Friend J, Snip RC, Kiorpes TC, et al. Insulin sensitivity and sorbitol production of the normal rabbit corneal epithelium in vitro. Invest Ophthalmol Vis Sci 1980;19:913-9.

44 Titone R, Zhu M, Robertson DM. Insulin mediates de novo nuclear accumulation of the IGF-1/insulin hybrid receptor in corneal epithelial cells. Sci Rep 2018;8:4378.

45 Bron AJ, de Paiva CS, Chauhan SK, et al. TFOS DEWS II pathophysiology report. Ocul Surf 2017;15:438-510.

46 Craig JP, Nelson JD, Azar DT, et al. TFOS DEWS II report executive summary. Ocul Surf 2017;15:802-12.

47 Dogru M, Katakami C, Inoue M. Tear function and ocular surface changes in noninsulin-dependent diabetes mellitus. Ophthalmology 2001;108:586-92.
48 Goebbels M. Tear secretion and tear film function in insulin dependent diabetics. Br J Ophthalmol 2000;84:19-21.

49 Sağdık HM, Ugurbas SH, Can M, et al. Tear film osmolarity in patients with diabetes mellitus. Ophthalmic Res 2013;50:1-5.

50 Johanna GPS, Antonio LA, Andres GS. Correlation between type 2 diabetes, dry eye and meibomian gland dysfunction. J Optom. In Press 2019

51 Yoon K-C, Im S-K, Seo M-S. Changes of tear film and ocular surface in diabetes mellitus. Korean J Ophthalmol 2004;18:168-74.

52 Dağdeviren M, Altay M, Yildiz Z, et al. The relationship between obesity, insulin resistance, and conjunctival impression cytology. Turk Patoloji Derg 2019;35:119-27.

53 Ansari AS, de Lusignan S, Hinton W, et al. The association between diabetes, level of glycaemic control and eye infection: cohort database study. Prim Care Diabetes 2017;11:421-9.

54 Zhang X, Zhao L, Deng S, et al. Dry eye syndrome in patients with diabetes mellitus: prevalence, etiology, and clinical characteristics. $J$ Ophthalmol 2016;2016:1-7.

55 Owen CG, Newsom RSB, Rudnicka AR, et al. Vascular response of the bulbar conjunctiva to diabetes and elevated blood pressure. Ophthalmology 2005;112:1801-8.

56 Khansari MM, Wanek J, Tan M, et al. Assessment of conjunctival microvascular hemodynamics in stages of diabetic microvasculopathy. Sci Rep 2017;7:45916.

57 von Thun Und Hohenstein-Blaul N, Funke S, Grus FH. Tears as a source of biomarkers for ocular and systemic diseases. Exp Eye Res 2013;117:126-37.

58 Grus FH, Sabuncuo P, Dick HB, et al. Changes in the tear proteins of diabetic patients. BMC Ophthalmol 2002;2:4.

59 Markoulli M, You J, Kim J, et al. Corneal nerve morphology and tear film substance $P$ in diabetes. Optom Vis Sci 2017;94:726-31.

60 Baca JT, Finegold DN, Asher SA. Tear glucose analysis for the noninvasive detection and monitoring of diabetes mellitus. Ocul Surf 2007;5:280-93

61 Lane JD, Krumholz DM, Sack RA, et al. Tear glucose dynamics in diabetes mellitus. Curr Eye Res 2006;31:895-901.

62 Sen DK, Sarin GS. Tear glucose levels in normal people and in diabetic patients. Br J Ophthalmol 1980;64:693-5.

63 Bruen D, Delaney C, Florea L, et al. Glucose sensing for diabetes monitoring: recent developments. Sensors 2017;17. doi:10.3390/ s17081866

64 Ding J, Liu Y, Sullivan DA. Effects of insulin and high glucose on human meibomian gland epithelial cells. Invest Ophthalmol Vis Sci 2015;56:7814-20.

65 Rocha EM, Cunha DA, Carneiro EM, et al. Identification of insulin in the tear film and insulin receptor and IGF-1 receptor on the human ocular surface. Invest Ophthalmol Vis Sci 2002;43:963-7.

66 Wu Y-C, Buckner BR, Zhu M, et al. Elevated IGFBP3 levels in diabetic tears: a negative regulator of IGF-1 signaling in the corneal epithelium. Ocul Surf 2012;10:100-7

67 Ozkan J, Willcox M, Wemheuer B, et al. Biogeography of the human ocular microbiota. Ocul Surf 2019;17:111-8.

68 Li S, Yi G, Peng H, et al. How ocular surface microbiota debuts in type 2 diabetes mellitus. Front Cell Infect Microbiol 2019;9:202.

69 Adam M, Balcı M, Bayhan HA, et al. Conjunctival flora in diabetic and nondiabetic individuals. Turk J Ophthalmol 2015;45:193-6.

70 Martins EN, Alvarenga LS, Höfling-Lima AL, et al. Aerobic bacterial conjunctival flora in diabetic patients. Cornea 2004;23:136-42.

71 Bilen $\mathrm{H}$, Ates $\mathrm{O}$, Astam N, et al. Conjunctival flora in patients with type 1 or type 2 diabetes mellitus. Adv Ther 2007;24:1028-35.

72 Fernández-Rubio ME, Rebolledo-Lara L, Martinez-García M, et al. The conjunctival bacterial pattern of diabetics undergoing cataract surgery. Eye 2010;24:825-34.

73 Ham B, Hwang HB, Jung SH, et al. Distribution and diversity of ocular microbial communities in diabetic patients compared with healthy subjects. Curr Eye Res 2018;43:314-24.

74 Kruse A, Thomsen RW, Hundborg HH, et al. Diabetes and risk of acute infectious conjunctivitis--a population-based case-control study. Diabet Med 2006;23:393-7.

75 American Academy of Ophthalmology Retina/Vitreous Panel. Preferred practice pattern guidelines. diabetic retinopathy. San Fransisco, CA: American Academy of Ophthalmology, 2016.

76 American Optometric Association. Eye care of the patient with diabetes mellitus. 2nd edn. St Louis, MO: American Optometric Association, 2019

77 Bastion MLC, Ling KP. Topical insulin for healing of diabetic epithelial defects?: a retrospective review of corneal debridement during vitreoretinal surgery in Malaysian patients. Med $\mathrm{J}$ Malaysia 2013;68:208-16.

78 Fai S, Ahem A, Mustapha M, et al. Randomized controlled trial of topical insulin for healing corneal epithelial defects induced 
during vitreoretinal surgery in diabetics. Asia Pac J Ophthalmol 2017;6:418-24.

79 Crockford D, Turjman N, Allan C, et al. Thymosin beta4: structure, function, and biological properties supporting current and future clinical applications. Ann N Y Acad Sci 2010;1194:179-89.

80 Sosne G, Rimmer D, Kleinman HK, et al. Thymosin beta 4: a potential novel therapy for neurotrophic keratopathy, dry eye, and ocular surface diseases. Vitam Horm 2016;102:277-306.

81 Sacks DB, Arnold M, Bakris GL, et al. Position statement executive summary: guidelines and recommendations for laboratory analysis in the diagnosis and management of diabetes mellitus. Diabetes Care 2011;34:1419-23.

82 Dunn SP, Heidemann DG, Chow CYC, et al. Treatment of chronic nonhealing neurotrophic corneal epithelial defects with thymosin beta 4. Arch Ophthalmol 2010;128:636-8.

83 Bonini S, Lambiase A, Rama P, et al. Phase II randomized, doublemasked, vehicle-controlled trial of recombinant human nerve growth factor for neurotrophic keratitis. Ophthalmology 2018;125:1332-43.

84 Abdelkader H, Patel DV, McGhee CN, et al. New therapeutic approaches in the treatment of diabetic keratopathy: a review. Clin Exp Ophthalmol 2011;39:259-70.

85 O'Donnell C, Efron N. Diabetes and contact lens wear. Clin Exp Optom 2012;95:328-37.

86 Bussan KA, Robertson DM. Contact lens wear and the diabetic corneal epithelium: a happy or disastrous marriage? J Diabetes Complications 2019;33:75-83.

87 Sheng H, Bullimore MA. Factors affecting corneal endothelial morphology. Cornea 2007;26:520-5.

88 Hugod M, Storr-Paulsen A, Norregaard JC, et al. Corneal endothelial cell changes associated with cataract surgery in patients with type 2 diabetes mellitus. Cornea 2011;30:749-53.
$89 \mathrm{He} \mathrm{X}$, Diakonis VF, Alavi Y, et al. Endothelial cell loss in diabetic and nondiabetic eyes after cataract surgery. Cornea 2017;36:948-51.

90 Fraunfelder FW, Rich LF. Laser-Assisted in situ keratomileusis complications in diabetes mellitus. Cornea 2002;21:246-8.

91 Bower KS, Woreta F. Update on contraindications for laser-assisted in situ keratomileusis and photorefractive keratectomy. Curr Opin Ophthalmol 2014;25:251-7.

92 Moshirfar M. Lasik in patients with diabetes mellitus, 2015. Available: https://eyewiki.aao.org/LASIK_in_Patients_With_Diabetes_Mellitus [Accessed Jan 2020].

93 Chunk RS, Jacobs DS, Lee JK, et al. Refractive errors \& refractive surgery PPP - 2017, 2017. Available: https://www.aao.org/preferredpractice-pattern/refractive-errors-refractive-surgery-ppp-2017 [Accessed Jan 2020].

94 Halkiadakis I, Belfair N, Gimbel HV. Laser in situ keratomileusis in patients with diabetes. J Cataract Refract Surg 2005;31:1895-8.

95 Lass JH, Riddlesworth TD, Gal RL, et al. The effect of donor diabetes history on graft failure and endothelial cell density 10 years after penetrating keratoplasty. Ophthalmology 2015;122:448-56.

96 Greiner MA, Rixen JJ, Wagoner MD, et al. Diabetes mellitus increases risk of unsuccessful graft preparation in Descemet membrane endothelial keratoplasty: a multicenter study. Cornea 2014:33:1129-33.

97 Vianna LMM, Stoeger CG, Galloway JD, et al. Risk factors for eye bank preparation failure of Descemet membrane endothelial keratoplasty tissue. Am J Ophthalmol 2015;159:829-34.

98 Briseno A, Jorkasky J, Levine M. New public opinion Poll reveals a significant number of Americans rate losing Eyesight as having greatest impact on their lives compared to other conditions, 2014. Available: https://cdn720.s3.amazonaws.com/eyeresearch/pdf/Poll_ press release.pdf [Accessed Nov 2019]. 